shown in Fig. 3 would yield an RTF replicon plus a polyR-determinant plasmid, whereas recombination between intermediately located IS units would yield a DNA molecule containing both an RTF segment and a varying number of R-determinant copies ${ }^{26}$. Thus, separate RTF and R-determinant replicons $s^{8-11}$, as well as plasmids containing multiple R-determinant copies ${ }^{30}$ could be produced from cointegrate $\mathbf{R}$ plasmids by the same recombinational process.

IS elements also seem to be involved in the recombination of $F$ plasmids with chromosal genes to yield $F^{\prime}$ plasmids ${ }^{31-33}$. The electron microscope heteroduplex studies of $\mathrm{Hu}$ and Davidson and their associates ${ }^{31-33}$ have identified three structurally defined DNA segments of $F$ that are hotspots for illegitimate recombination events that do not require bacterial $r e c \mathrm{~A}$ gene function. One of these, the $\varepsilon \zeta$ sequence, is homologous with IS2 (ref. 29). A second recombinationally active segment on $\mathrm{F}$, the $\alpha \beta$ sequence, is indistinguishable from the IS3 element ${ }^{33}$. Formation of an $\mathrm{Hfr}$ cell by integration of $\mathrm{F}$ into the chromosome can occur by interaction of the plasmid with an IS element inserted in either of two polarities. In 23 of 25 independently derived Hfrs, the point of origin and the direction of transfer of the chromosome by the integrated $F$ plasmid could be predicted by the polarity of the $\alpha \beta$ or $\varepsilon \zeta$ sequence on the plasmid ${ }^{32,33}$. Taken together, these various data strongly suggest that IS sequences are involved in $\mathrm{Hfr}$ formation. These studies ${ }^{31-33}$ suggest also that IS elements have a prominent role in the acquisition of chromosomal genes by plasmids and indicate that deletions of F-plasmid DNA can occur during $F^{\prime}$-plasmid formation, and that one endpoint of the delegated DNA scgment of ten is coincident with the endpoint of an IS element.

\section{Translocation (transposition) of DNA segments carrying antibiotic resistance genes}

In 1964 Dubnau and Stocker ${ }^{34}$ reported that antibiotic resistance genes from a plasmid could become associated with the P22 prophage and subsequently attach to the chromosome of Salmonella typhimurium. Kondo and Mitsuhashi observed that $E$. coli phage P1 could similarly receive a resistance gene from a plasmid ${ }^{3 s}$. I.ater, Mitsuhashi and coworkers ${ }^{37,38}$ described the spontaneous integration of R-plasmid genes for choramphenicol $(\mathrm{Cm})$ resistance at various sites of the $E$. coli chromosome, and the subsequent movement of the $\mathrm{Cm}$ resistance trait on to another $\mathrm{R}$ plasmid or on to bacteriophage $\mathrm{P1}$, which could then transfer the resistance interbacterially. Other observations from the same laboratory suggested that Tc-resistance genes

\title{
Abbreviated Rules of Nomenclature for transposable elements of DNA*
}

\section{Definition}

Transposable elements are DNA segments which can insert into several sites in a genome.

\section{Classes of element}

(1) IS (simple insertion sequences): contain no known genes unrelated to insertion function, generally shorter than $2 \mathrm{~kb}$. Symbols: IS1, IS2, IS3 and so on.

(2) Tn (more complex, transposable elements, often containing IS elements): behave formally like IS elements, but contain additional genes unrelated to insertion function, generally larger than $2 \mathbf{k b}$. Symbols: $\operatorname{Tn} 1, \operatorname{Tn} 2, \operatorname{Tn} 3$ and so on. A different number is assigned to each independent isolate from nature, even if it is apparently identical to some previous isolate. The designations assigned in the accompanying table to some known Tn elements should be used in all publications.

(3) Episomes (complex, self-replicating elements often containing IS and Tn elements).

\section{Organisms and genomes with inserted clements}

(1) Organisms. When an inserting element has been introduced into a previously described bacterial strain, the new strain should be given an isolation number. Its genotype can be denoted by the genotype of the parent strain, followed by the name of the elcment in parentheses.

(2) Genomes. If location is known, specify genc or region in which element is inverted, followed by a number designating the particular insertion mutation, then by double colon and finally by name of inserted element; for example, ga/T-236:: IS 1 (IS/ within gene galT).

\section{Central registry}

To avoid duplications of numbers, all new IS and Tn elements should be checked with a central registry before numerals are assigned to them in publications. A registry for Tn elements will be maintained by Esther Lederberg, Department of Medical Microbiology, Stanford University Medical School, Stanford, California 94305 (USA) as part of the Plasmid Reference Center.

\begin{tabular}{cllc}
\hline \multicolumn{4}{c}{ Designation of Tn elements* } \\
\hline Element ${ }^{*}$ & $\begin{array}{l}\text { Plasmid } \\
\text { origin+ }\end{array}$ & $\begin{array}{c}\text { Resistance } \\
\text { markers\$ }\end{array}$ & References \\
Tn1 & RP4 & Ap & 6 \\
Tn2 & RSF1030 & Ap & 7 \\
Tn3 & R1 & Ap & 8 \\
Tn4 & R1 & ApSmSu & 8 \\
Tn5 & JR67 & Km & 2 \\
Tn6 & JR72 & Km & 2 \\
Tn7 & R483 & TpSm & 1 \\
Tn9 & pSM14 & Cm & 4 \\
Tn10 & R100 & Tc & 3,5 \\
\hline
\end{tabular}

†The symbol Tn 8 has not yet been assigned.

Natural plasmid from which clement originated.

$\$ \mathrm{Ap}=$ ampicillin; $\quad \mathrm{Sm}=$ streptomycin; $\quad \mathrm{Su}=$ sulphonanide; $\mathrm{Km}=$ kanamycin; $\mathrm{Tp}=$ trimethoprim; $\mathrm{Tc}=$ tetracycline.

IBarth, P. T., Datta, N., Hedges, R. W., and Grintner, N. J., J. Bact. $125,800-810$ (1976).

2 Berg, D. E.. Davies, J., Allet, B., and Rochaix, J., Proc. natn. Acad. Sci. U.S.A., 72, 3628-3632 (1975).

Foster, T. J., Howe, T. G. B., and Richmond, K. M. V., J. Bact., $124,1153-1158(1975)$.

4 Gottesman, M., and Rosner, J. L., Proc. natn. Acad. Sct. U.S.A., 72, $5041 \ldots 5045$ (i 975$)$.

Kleckner, N., Chan, R., Tye, B., and Botstein, D., J. molec. Biol., 97,

$561-575$ (1975).
6 Hediges, R. W., and Jacob, A. E., Molec. wen. Genet., 132, 31 40

(1974).
I lelfron, F., Sublett. R., Hedges, R. W., Jacob ,A., and Falkow, S., J. Bact., 122, 250-276 (1975). Kopecko, D. J., and Cohen, S. N., Proc. natn. Acurd. Sci. U.S.A., 72

*Prepared by a committee consisting of A. Campbell (chairman), D. Berg, D. Botstein, R. Novick and P. Starlinger. The complete report will appear in DNA Insertion Elements, Plasmids and Episomes (Cold Spring Harbor Laboratories, Cold Spring Harbor, in the press). 